\title{
Knowledge Translation Capacity of Arts-informed Dissemination: A Narrative Study
}

\author{
Jennifer L. Lapum ${ }^{1}$ \\ Ryerson University \\ jlapum@ryerson.ca \\ Linda Liu \\ Toronto General Hospital \\ linda.y.liu@ryerson.ca \\ Sarah Hume \\ Ryerson University \\ shume@ryerson.ca \\ Siyuan Wang \\ Ryerson University \\ siyuan.wang@ryerson.ca \\ Gideon Cohen \\ Sunnybrook Health Sciences Centre \\ Gideon.Cohen@sunnybrook.ca \\ Kathryn Church \\ Ryerson University \\ k3church@ryerson.ca \\ Bailey Harding \\ Ryerson University \\ bharding@ryerson.ca \\ Megan Nguyen \\ Women's College Hospital \\ megan.nguyen@ryerson.ca \\ Terrence M. Yau \\ Toronto General Hospital \\ terry.yau@uhn.on.ca
}

\begin{abstract}
Arts-informed dissemination is an expanding knowledge translation approach in the health sciences. Problematic is the minimal evaluation studies and the rare reporting of the influencing factors of knowledge translation. "The $7,024^{\text {th }}$ Patient" is a research-derived art installation created to disseminate findings about patients' experiences of heart surgery and the importance of patient-centred care approaches. This arts-informed narrative study explored how arts-informed dissemination influenced healthcare practitioners' delivery of care. Two interviews were conducted (at the time of viewing the installation and 6 months later) with a multi-disciplinary group of 19 individuals who worked with patients undergoing heart surgery. Study findings indicated that the arts as a form of evidence provide an experiential encounter, which stimulated reflective practice. Participants' accounts reflected cognitive and behavioral modifications related to empathy, holistic approaches and relational care. However, the complexities associated with the interpretive process indicated a need for a more dialogical approach to the translation process, including deconstructing the evidence within the context of one's own practice. Next steps require the examination of the knowledge translation capacity of different art forms with a range of populations and disciplines.
\end{abstract}

Keywords: Arts-based research; dissemination; knowledge translation; cardiovascular population; aesthetics; implementation science; research uptake; installation art; poetry, photographic imagery

\section{Background}

\footnotetext{
${ }^{1}$ Biographical statements: Dr. Jennifer L. Lapum, PhD, MN, BScN, RN, Associate Professor, Ryerson University. Dr. Lapum is an arts-based researcher and poet in the health sciences. Her program of research focuses on ensuring that the $7,024^{\text {th }}$ patient does not feel like the $7,024^{\text {th }}$ patient. Linda Liu, MN, BScN, RN, Registered Nurse, Toronto General Hospital. Dr. Kathryn Church, PhD, MA, BA, Director and Associate Professor, School of Disability Studies, Ryerson University. Sarah Hume, BCom, BScN, Ryerson University. Bailey Harding, BHK, BScN, Ryerson University. Siyuan Wang, BScN, Ryerson University. Megan Nguyen, MN, BScN, RN, Research Coordinator, Women's College Hospital. Gideon Cohen, MD, MSc, PhD, Staff Surgeon, Schulich Heart Centre, Sunnybrook Health Sciences; Associate Professor, University of Toronto. Terrence M. Yau, MD, BA, MSc, Surgeon, University Health Network; Director of Research, Division of Cardiovascular Surgery Toronto General Hospital; and Professor of Surgery, University of Toronto.
} 
The knowledge translation (KT) process spanning generation to application (Canadian Institutes of Health Research, 2012) is vital to consider in order to facilitate research uptake into practice (Rycroft-Malone, 2004). Additionally, research uptake enhances the quality of healthcare practice by ensuring that current practice is evidence-based. KT's ultimate outcome is that knowledge users are aware of and apply current evidence to shape healthcare policies, decision-making, and practice (Grimshaw, Eccles, Lavis, Hill, \& Squires, 2012). Dissemination is a key component of KT (Reardon, Lavis, \& Gibson, 2006; Strauss, Tetroe, \& Graham, 2009; Ward, House, \& Hamer, 2009) and typically occurs through publications. However, optimal research uptake has proven to be problematic (Cummings, Estabrooks, Midodzi, Wallin, \& Hayduk, 2007; Grimshaw, et al., 2012).

Arts-informed approaches have emerged as legitimate forms of research (Boydell, Gladstone, Volpe, Allemang, \& Stasiulis, 2012) showing promise to enhance KT. These approaches involve using the arts in any phase of the research process (Knowles \& Cole, 2008). Evidence suggests that common arts media in research include theatre, dance, visual arts, poetry, and installation art (e.g., Angus, et al., 2009; Boydell, 2011; Carless \& Douglas, 2009; Cox, Kazubowski-Houston, \& Nisker, 2009; Faulkner, 2007; Fraser \& al Sayah, 2011; Lahman, et al., 2010; Lapum, Ruttonsha, Church, Yau, \& Matthews David, 2012; Radley \& Taylor, 2003; Rich, Polvinen, \& Patashnick, 2005; Richardson, 2002; Rossiter, et al., 2008; Stuckey, 2009; Stuckey \& Tisdell, 2010). Although the arts have been increasingly incorporated into healthcare research over the last decade, they have well-established roots in education and sociology (Boydell, et al., 2012; Knowles \& Cole, 2008). Arts-informed research approaches have also been documented in fields such as medicine, nursing, epidemiology, health policy, sociology, psychology, neuroscience, and rehabilitation science (Boydell, et al., 2012; Fancourt \& Joss, 2015). The main findings of a scoping review, conducted by Boydell, et al. about arts-informed research, were that the arts promote audience engagement and enhance awareness of the illness experience.

In research, the arts can be used to facilitate knowledge production or dissemination (Boydell, et al., 2012; Fraser \& al Sayah, 2011; Leichner \& Wieler, 2015) and inform clinical practice and policy (Parsons \& Boydell, 2012). There is increasing empirical support regarding the effectiveness of using the arts to learn about illness experiences (Colantonio, et al., 2008; Gray, Fitch, Labreque, \& Greenberg, 2003; Kontos \& Naglie, 2007; Lapum, et al., 2014; Mitchell, Jonas-Simpson, \& Ivonoffski, 2006; Sinding, Gray, Fitch, \& Greenberg, 2006). Scholars have identified a positive impact when using art-making or the arts to inform pedagogies in healthcare professional education (Cox, Brett-MacLean, \& Courneya, 2016; Lapum, Hamzavi, et al., 2012). However, our work was specifically interested in the use of arts as a research dissemination method. Arts-informed dissemination has the power to elicit affective responses (Lapum, Ruttonsha, et al., 2012; Parsons \& Boydell, 2012) prompting reflection and dialogue while engaging practitioners on emotive, embodied, and intellectual levels (Charon, 2006b; Lapum, 2005; Leggo, 2004; Leichner \& Wieler, 2015; Macbeth, 2001). The sensory experiences provoked by the arts permit individuals to 
feel and see aspects of the human condition (Eisner, 2008), thereby illuminating dimensions of patients' experiences (Lapum, Ruttonsha, et al., 2012). Incorporating the arts into research dissemination has potential to prompt practice modifications (Gray, et al., 2003; Mitchell, et al., 2006) and policy changes to better meet patients' needs (Leichner \& Wieler, 2015).

Scholars have begun to evaluate peoples' responses to arts-informed dissemination (Kontos \& Naglie, 2007; Mitchell, Dupuis, \& Jonas-Simpson, 2011; Shapiro \& Hunt, 2003; Sinding, et al., 2006). Research has overwhelmingly indicated positive responses in which arts-informed dissemination enhances individuals' understanding about illness and patients' experiences (Colantonio, et al., 2008; D'Alessandro \& Frager, 2014; Gray, et al., 2003). The research about how arts-informed dissemination influences practice over time (Gray, et al., 2003; Lapum, et al., 2014), however, has been limited. In one study, a team examined how research-based theatre about cancer influenced practice for up to six months (Gray, et al., 2003). They found that practitioners modified communication so that they broached sensitive topics with patients and altered decision-making so that it was more inclusive of patients (Gray, et al., 2003). There is a pressing need to continue to explore the short and particularly the long-term impact (Boydell, et al., 2012; Parsons \& Boydell, 2012) of arts-informed dissemination on practice in order to further evaluate its role in healthcare.

In this article, we share findings from a study that explored how knowledge from a research-derived art installation ${ }^{2}$ influenced cardiovascular practitioners' delivery of care. The images included throughout the discussion provide a sense of the art installation. This short promotional video provides an overview of the installation:

\section{https://ualberta.aviaryplatform.com/r/3n20c4t97s}

\section{The Art Installation: An Arts-informed Dissemination Method}

This art installation was based on a narrative study about patients' experiences of heart surgery, which featured the themes of mortality, vulnerability, bodily intrusion, loss of control, fear, displacement, self-preservation and renewal of life. The main finding was that humanistic approaches to person-centred care (PCC) mattered (Lapum, Angus, Peter, \& Watt-Watson, 2010, 2011). This finding corroborated earlier research that emphasized the need for tailored patient care and integration of psychological, social, and affective dimensions of recovery from surgery (e.g., Allen \& Wellard, 2001; Angus, 2001; Dingley, Bush, \& Roux, 2001; Keller, 1991; King, 2000; King \& Jensen, 1994; King, Rowe, Kimble, \& Zerwic, 1998; Murray, O'Farrell, \& Huston, 2000; Plach \& Heidrich, 2001, 2002). Humanistic approaches ask practitioners to question what it means to be ill (Charon, 2006a). This element of PCC is important so that practitioners can empathetically shift their frame of reference to patients and

\footnotetext{
${ }^{2}$ For more information on the art installation "The $7,024^{\text {th }}$ Patient", see the project website (http://the 7024thpatient.com/?portfolio=the-7024th-patient-2).
} 
engage in compassionate forms of practice. Humanistic approaches have continued to be neglected (Lapum, 2009) despite these study findings.

Considering the evidence for both humanistic approaches to PCC and the KT possibilities of the arts, the first author of the narrative study formed an interdisciplinary team to design an art installation, "The 7,024 ${ }^{\text {th }}$ Patient," to disseminate the study findings (Lapum, Ruttonsha, et al., 2012). Patients' stories were translated into poetry and metaphorically represented through photographic images, imprinted on hanging textiles. The 1,739 square foot and $91 / 2$ foot tall (or 530 square metres and 2.9 metres tall) installation was designed to allow viewers to follow patients' journeys. Details about the installation's design process (Lapum, Ruttonsha, et al., 2012), as well as its poetry and imagery (Lapum, Church, Yau, Matthews David, \& Ruttonsha, 2012; Lapum, Church, Yau, Ruttonsha, \& Matthews David, 2013; Lapum, Yau, \& Church, 2015; Lapum, Yau, Church, Ruttonsha, \& Matthews David, 2015), have been published elsewhere. Because this was a novel dissemination method, we conducted preliminary research about peoples' responses to the installation, including interviews, focus groups, and written comments from physicians, nurses, allied health professionals, administrators, patients, and other visitors. Analysis revealed that the installation provided a glimpse into the internalized space of patients' minds and bodies and transported viewers into the emotional and physical experience of heart surgery (Lapum, et al., 2014). These findings also indicated that the installation stimulated critical reflection about potential practice modifications (Lapum, et al., 2014).

In the study's third phase, which is reported here, we focused on how this research-derived art installation influenced cardiovascular practitioners' delivery of care and the KT factors that influenced research uptake. Ethics approval was received from the first author's institution and the institution where the art installation was displayed.

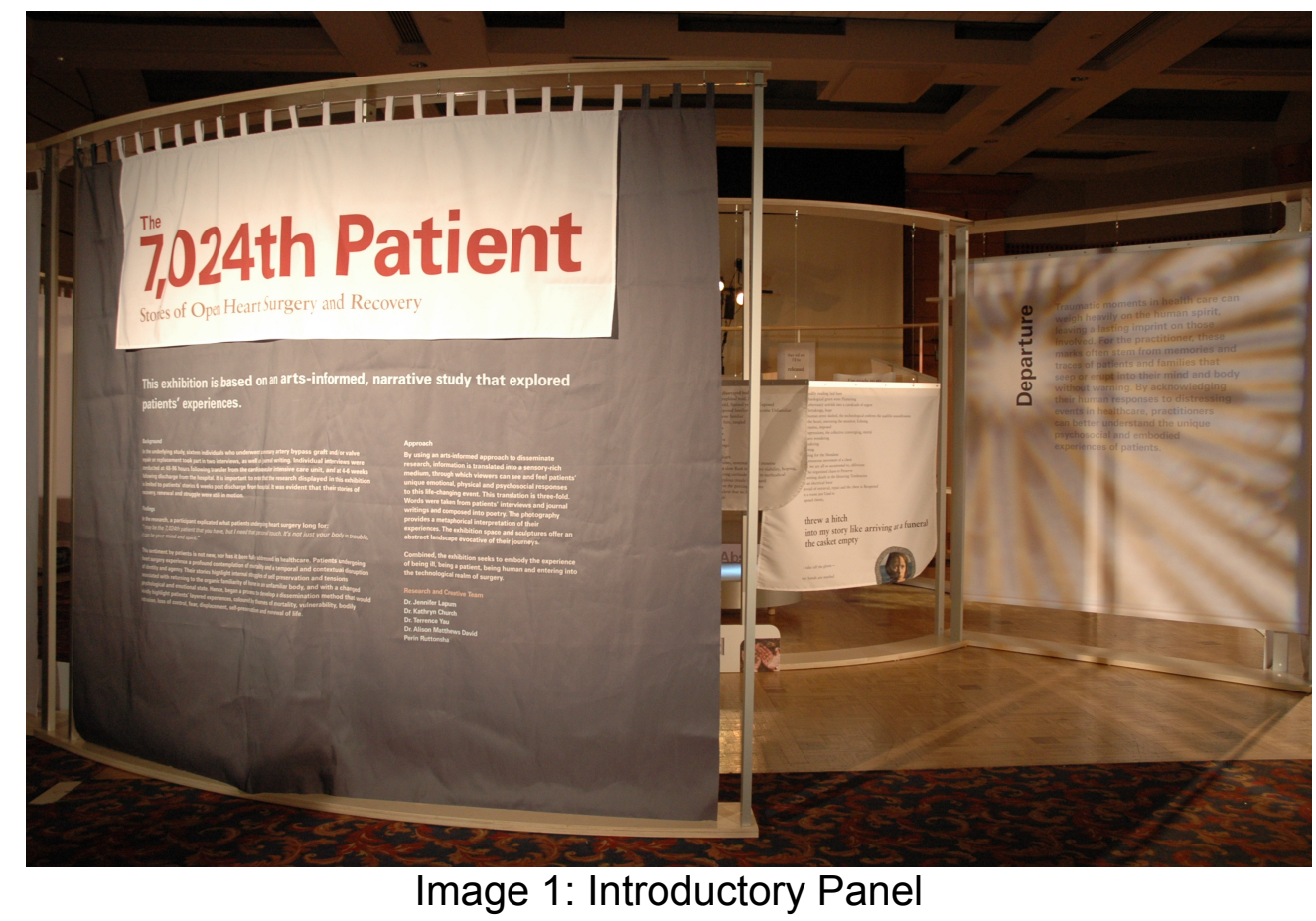




\section{Methods}

We used an arts-informed narrative methodology drawing upon Bresler (2006) and Lieblich, Tuval-Mashiach, and Zilber (1998). Specifically, we drew upon a narrative methodology that focused on stories including content (what story is told - plot, characters, situations, outcomes) and form (how the story is told - metaphor, vocal intonation, discourse) (Lieblich, et al., 1998; Lieblich, Zilber, \& Tuval-Mashiach, 2008). Stories provide insight into practitioners' specific context, which was important in this project as it helped clarify how knowledge derived from the installation influenced practice. The arts were integrated into data analysis to provide further attunement to the aesthetic qualities of stories. Incorporating aesthetic qualities of respondents' narratives (Bresler, 2006) helped refine our understanding of the sensory qualities of stories (e.g., What happened? What did it feel like? What did it look like?). Thus, an arts-informed narrative methodology provided us with a contextualized understanding of how practitioners translated knowledge from the installation into their specific environments.

This study was informed by the Promoting Action on Research Implementation in Health Services (PARiHS) framework, which highlights the interplay of the multiple influencing KT elements including evidence, context, and facilitation (Kitson, et al., 2008; Rycroft-Malone, 2004; Rycroft-Malone, et al., 2009). In our study, the PARIHS framework served as a theoretical lens to clarify ways these elements influenced how individuals made sense of and translated arts-informed evidence into practice. These elements were important to consider because the evidence for humanistic approaches is abstract and interpretive and, thus, involved complex application that was contingent on the practitioner, patient, and context. The framework facilitated our development of the interview guide so that we were well positioned to probe participants about the influencing elements of KT as well as inform our analytic insights. For example, the PARiHS framework directed attention to the nature of the arts as a form of evidence as well as the facilitators and barriers to implementation within the context of the practitioner's own settings. A narrative methodology facilitated our understanding of these KT elements, because storied accounts provided rich description of the processes that individuals took to determine whether evidence is relevant, and explicated the influencing factors involved in research implementation. Participants' narratives highlighted the processes related to weighing the benefits and risks of implementing the evidence, its applicability to the patient population that they are serving, and negotiating whether and how their practice area was conducive to implementation of the evidence.

The installation was displayed for one week at a hospital in Toronto, Canada, and promoted through social media and local hospital, academic, and community electronic mailing lists. Using purposive sampling, we recruited knowledge users who worked with patients undergoing and recovering from heart surgery. After individuals walked through the installation, they were approached by research staff members, informed about the study, and invited to participate if they worked with this population. We recruited 19 individuals ( 14 female and 5 male) from multiple institutions, including physicians $(n=2)$, physiotherapists $(n=2)$, ethicists $(n=1)$, pharmacists $(n=1)$, speech language pathologists $(n=1)$, advanced practice nurses $(n=2)$, and registered nurses 
$(n=10)$, with the latter being the largest group, which is reflective of the population. Years worked with the cardiovascular population ranged from one to 28. Installation viewing times ranged from 15 to 90 minutes.

Two narrative-based interviews were conducted with each participant: the first within 48 hours of viewing the installation and the second at 6 months post-viewing. Although an emergent interviewing process was followed to enable question construction based on participants' responses, a selection of standard questions included: Tell me about your initial response to the installation. Has the installation affected the way you deliver patient care? If so, please tell me about this. Has your institutional culture influenced the way that you have garnered knowledge from the installation and applied it in practice?

Data were collected and analyzed simultaneously, which enabled early interviews to inform later ones. This process also allowed for a rigorous approach to the analysis considering that narrative researchers are the research instruments (Josselson, Lieblich, \& McAdams, 2003). Our approach to narrative research was located in the interpretive paradigm and thus, reflexive engagement in the research and analysis was vital. As a team, this approach involved constant questioning and inquiry during the analytic phase and always considering alternative explanations of the data (Lieblich, et al., 1998). Transcripts were subjected to a narrative analysis focused on both story content and form (Lieblich, et al., 1998). The analytic process involved a focus on the shaping forces and structures of stories, including plot, characters, situations, and outcomes (Lieblich, et al., 1998; Lieblich, et al., 2008) so that both nature of evidence and quality of context were evaluated in terms of research implementation. By attending to these structures, as well as linguistic and rhetorical devices (e.g., metaphors, images, vocal intonations, repetition), insight was gained into the personal and cultural forces of stories (Doucet \& Mauthner, 2008; Kleinman, 1988), as well as KT elements related to evidence, context, and facilitation (Rycroft-Malone, et al., 2004).

The arts were embedded in the analytic processes through the use of Pictorial Narrative Mapping. Pictorial Narrative Mapping is an analytic technique involving aesthetic attunement to data in which the narrative plotline is visualized (Lapum, Liu, et al., 2015). The design processes were anchored closely in the data as we made decisions using a systematic, dialogical, and reflexive approach about the picture's composition, form, emotional tone, medium, and textures (Lapum, Liu, et al., 2015). The process resulted in a picture that visually mapped each participant's narrative (Lapum, Liu, et al., 2015). Looking across these pictures, recurring narrative ideas emerged. 


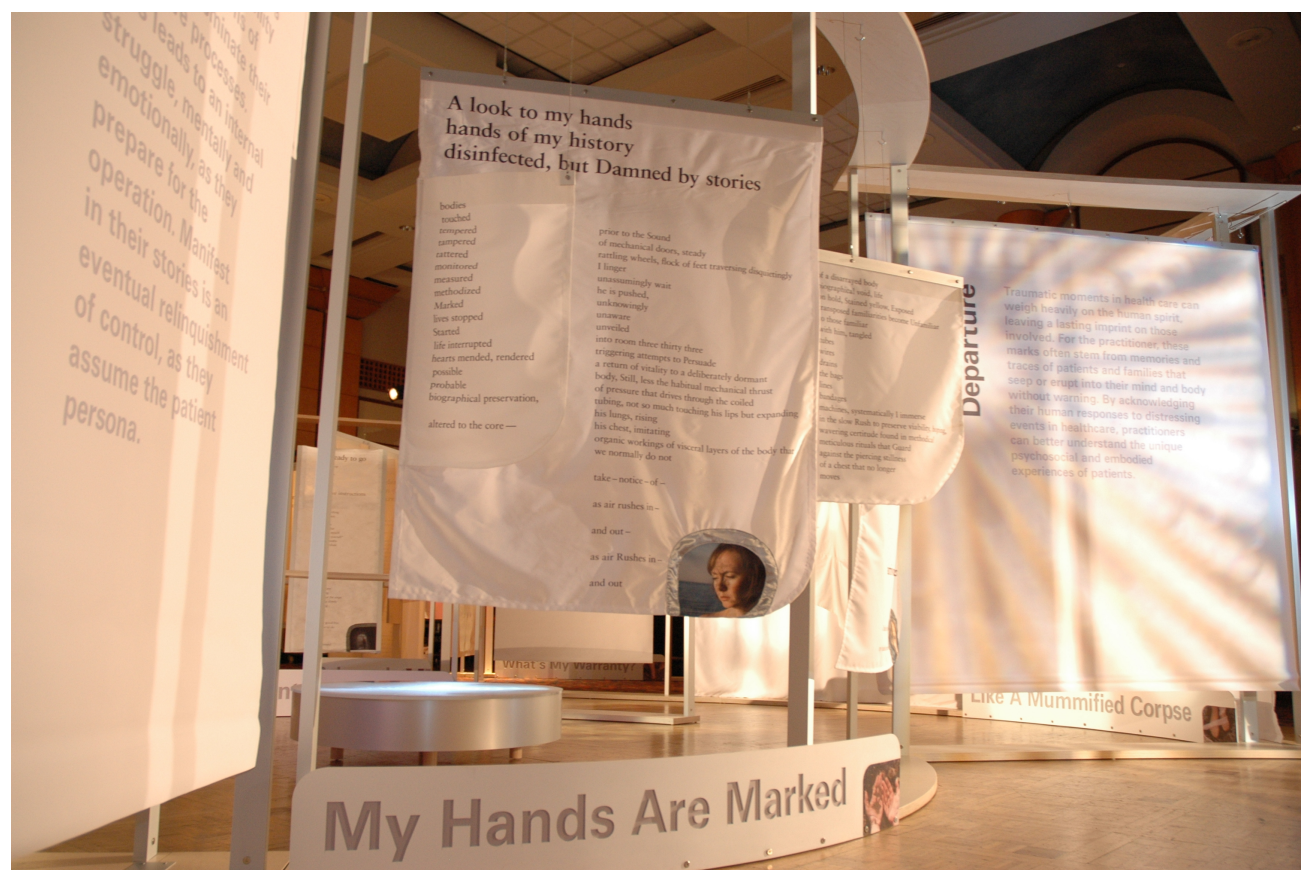

Image 2: Zone 2 - My Hands Are Marked

\section{Results}

Study results are presented according to three narrative ideas related to practice changes that shift from cognitive to behavioral manifestations: empathy, holistic care approaches, and relational care. This dissemination format provides the opportunity for knowledge users to make sense of participants' narratives through story excerpts. Although some participants were surprised by patients' experiences, many indicated that the installation was a reminder and validation about the importance of humanistic PCC approaches despite dominant discourses of efficiency in healthcare systems. While discussing the narrative ideas in this section, we also explicated elements of KT specifically related to the type of evidence and the institutional context (Rycroft-Malone, 2004). Throughout our data analysis, we found that evidence and institutional context were the key elements of KT that appeared in participants' narratives to facilitate and inhibit the process of research uptake. Our interpretive comments concerning these elements are explicated before and after participant quotes as appropriate.

Empathy. We found that participants' empathetic responses began when their senses were stimulated through the aesthetics of the arts as a form of evidence. Participant seven (P7) said that the installation "made you kind of immersed ... you really kind of feel" a patient's experience. She indicated that empathetic connections are "what people are desperate for", which emphasizes their vital importance. P3 stated, "I saw glimpses into the patient's experience that l'd never imagined. ... I'd never thought about what they might go through." Some participants however suggested that the installation did not necessarily contain new knowledge: "I always knew ... what the patient was going through" (P10). Nonetheless, P10 elaborated that the installation made her "more aware of ... what the patients worried about." P18 stated that, "you can 
feel what this patient was feeling" when viewing the art installation as compared to an article. P12's comments about the installation reflect most participants' responses. She stated that the installation "attacks different senses ... than just reading an article" and that she was "never really going to forget the visual of that," which emphasizes the enduring nature of this type of evidence for all participants except one. P19's comment implied limited memory of the installation: "You forget ... probably need repeated exposures." His feedback suggests the need for repetition in the KT process. Possibly linked with his inability to recall details of the installation six months later was his own personal appraisal of its relevance to his discipline. He stated that the installation was "enlightening," but felt that "it's not something you [as a pharmacist]... probably delve into." However, he indicated that he was also removed from the bedside in his work. Predominantly, participants' comments highlight both the aesthetic component of artsinformed evidence and their emotive reactions to the installation.

Art, as a form of research evidence, was shown to prompt a kinesthetic and sense-based experience. P17 described a "sensation ... [it was] very visceral" as a result of the artistic presentation of the evidence. P2 remarked, "Reading their concerns, you kind of, like you're, like you're at the bedside, like you're really hearing [them]." His comment points to how the arts stimulate the auditory senses and create a transportative shift. According to P16, the installation, in contrast to a journal article, "drew you in and carried you through ... it forced you to journey through that experience." Her comments suggest that the installation created an active experience that had a persuasive power influencing participants to imaginatively travel alongside patients. Additionally, her comment reflects that "how" evidence is communicated is vital to the KT process. Referring to a poetical piece designed in a spiral that is symbolic of loss of consciousness during the operative period, P7 commented that the words "spoke to me ... the flow of how it was presented ... especially the section where you walked around because even that movement made me feel, it is a journey for patients." P7's response demonstrates how, in addition to affecting the auditory senses, the installation's design necessitated viewers' movement in a way that resembled a patient's experience. The following comments about the installation reflect one way in which the arts as a form of evidence create a kinesthetic experience for participants and activate the senses:

It made me look in different angles and the lighting actually started casting shadows ... I was influencing it by moving the shadows. ... you had to turn your head and look at the different poetry and also from the kind of cocooned feeling that you were in an experience. ...sort of surrounded by not just the walls but the words. (P17)

The research thus far expands ideas about the KT element of evidence in terms of how the arts can establish conditions for an experiential opportunity; and this experience has the capacity to create a visceral encounter and active interaction with the evidence rather than just facilitate abstract reflection at a distance.

The art installation acted in ways to enhance capacity for empathy. P2 stated that the installation was like "Alice in Wonderland ... I feel like actually I'm in the patient's world." This metaphorical reference highlights a larger-than-life and other worldly 
experience, whereas another participant described it like "a journey ... I was exploring what patients go through" (P3). It appears that the nature of the evidence form, in this case the arts' aesthetic components, enhance the possibility for an empathetic shift:

I noticed the lights ... shining behind me, you could, like I could see my own silhouette so it kind of puts you into [a patient's] position like it almost makes you think like you're the person that's saying these words ... as if I were in the patient's shoes. (P8)

These excerpts point to the ways in which the installation influenced viewers so that they actively experienced the dissemination method and shifted to a patient's frame of reference. P17 indicated that the installation enhanced her capacity for "empathy ... to relate in a better way." She explicated how the installation "created a different mental model" for her and how this influenced her practice:

Whereas I kind of looked at the world of patient care through the eyes of the provider, that it [the installation] really shifted my thinking not just, here I can gain more empathy for the patient, but the things that they were thinking about versus what I thought they were thinking about ... so having to stop myself from thinking in that manner and really be a bit more curious about what their experience is. (P17)

In addition to showing how the installation shifted her frame of reference, this excerpt also reveals how curiosity plays a role in being empathetic. This participant was inspired to ask more questions and inquire about the patients' experiences. Practitioners' immersion into the installation disrupted their assumptions and instead prompted them to elicit a patient's perspective.

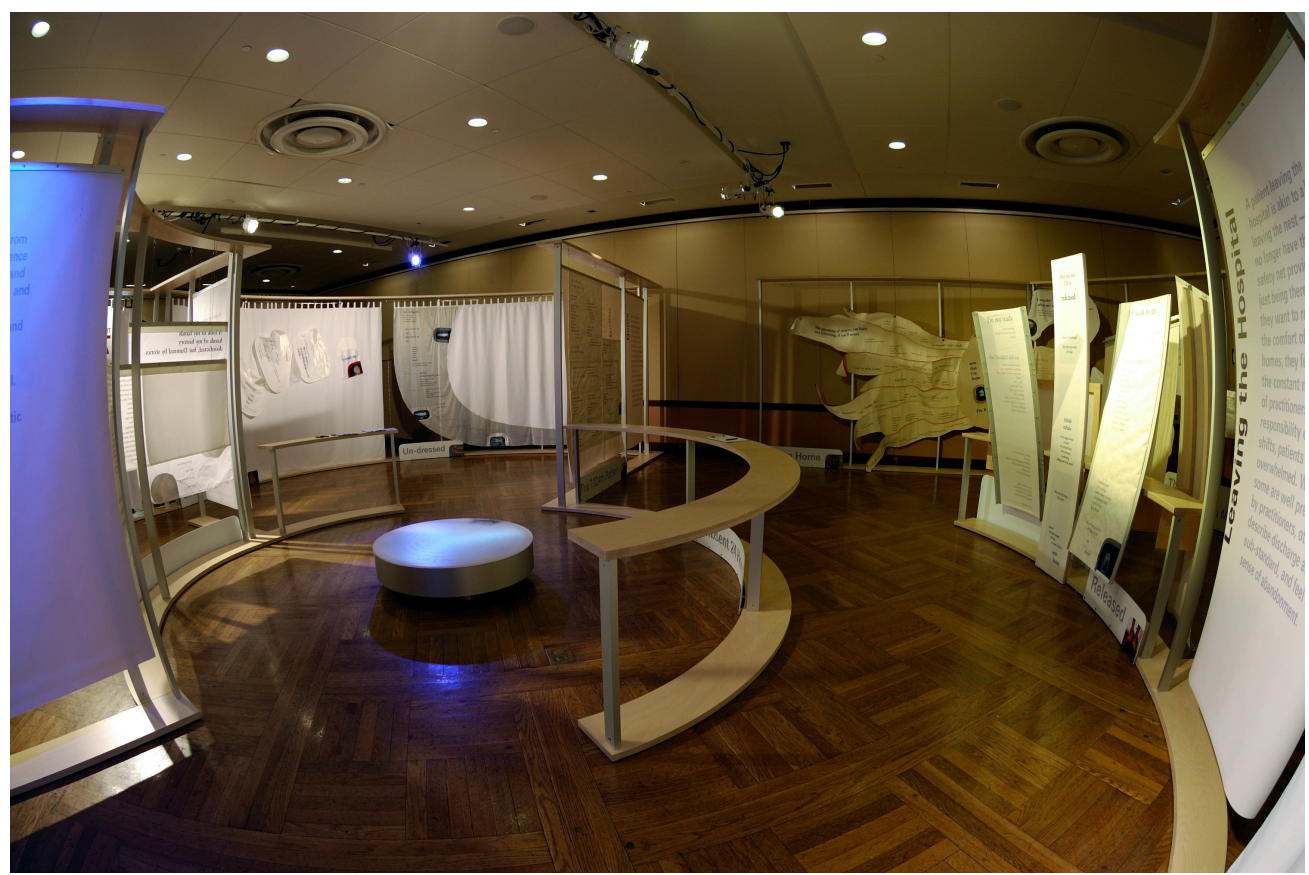

Image 3: Installation Overview 
Holistic patient care approaches. The art installation led participants to enhance holistic care approaches. P15 stated that the most important thing she garnered was the need for "patient-centred care that focused on the humanistic, the holistic ... respecting [patients'] wishes." She explained that the installation impacted her because "the photography and combining with words, I think speaks louder ... feels like someone is speaking to you ... in words that are so implanted in your mind, so vivid. You can just feel the words." This excerpt and the linguistic usage of "implanted" suggests that the blend of poetry and photography as a form of evidence provides a personal encounter and has the quality of firmly rooting in one's thinking. When P8 used the plural pronoun "we" in her comment that the installation was a "reminder that we need to look at the whole picture, not just ... numbers," she not only emphasized holistic care approaches, but also suggested a collective responsibility. As a result of the installation, P11 referred to herself as a more "holistic" and "nurturing" caregiver. She referred to doing "little things" for patients, stating, "it doesn't mean I'm having some detailed conversation with them," but just making the patient more "comfortable ... secure." Her statement suggests that these practice modifications were effortless. Additionally, underlying other participants' comments were KT barriers and facilitators of engaging in holistic care approaches: "If caseload demands are more reasonable then you can spend more time ... just more holistically, [taking care of] all of their needs" (P11). P12 referred to practices that would facilitate holistic care, such as support groups and meetings with nutritionists, stating that, "all of these supports were cut because they were considered to be soft." This excerpt indirectly highlights the discourse associated with a biomedical focus and system barriers related to costs. Linking back to the PARiHS framework, institutional contexts that place value on holistic approaches to care and operationalize this value with the provision of adequate staffing would be optimal for research uptake.

The installation acted as a tool to refresh practitioners' appreciation of individualized care. P4 indicated that based on the installation, it is important to "not forget that every patient has a unique experience." His statement suggests that it may be easy to unintentionally omit patients' individuality. P16, who elaborated that the installation "reinforced" her practice in terms of the importance of "being more patient centred," stated that it reminded practitioners that patients are "living, breathing persons with a past, a present and a future and what that is, we don't know, that journey is very unique to them." This excerpt suggests a temporal and concealed nature to the patient experience that practitioners need to seek out. P11 commented, "I don't think individual needs are always considered," but she also felt that, as a physiotherapist, it was "not my area of expertise." In terms of best practices derived from the installation, P12 referred to mentoring others about individualized approaches to patient care. She stated that you need "to peel away some of the other parts and see what's really going on" with patients. Elaborating on what she would tell practitioners, she remarked: "It's not just one more bypass, it's not just one more valve replacement; this is life changing, for people, so this is something I came away with as an overall, from that, and tried to remember that" (P12). Her statements reflect an inner and unique element of illness in which patients need to be looked at individually and not grouped as a specific surgical population. P11 commented that the installation "highlighted the human aspect ... sometimes you can just cycle through a bunch of cases, but ... they all have individual 
experiences." Her linguistic use of "cycle through" suggests a regularly repeated sequence of events associated with her practice that risks overshadowing patients' unique experiences. Additionally, her comments suggest that the arts as a form of evidence create a space to connect with the patient as a human being.

Commonly reflected in participants' narratives were holistic approaches that moved beyond the physical body. P13 commented on her practice changes, "I've tried to witness more ... I'm watching to see where [a patient's] state of mind is, and addressing it." She further stated that the installation "played on my mind ... those words were just so powerful and so honest ... like a cold hard fact." P13's phrasing suggests the installation demonstrated solid evidence as well as occupied a space in her mind that led to practice modifications. According to P15, the installation will "always remind [her] ... [to care for] the deepest part of the person including their emotional being." P15's comment alludes to the installation's enduring impact on her and the need to maintain a holistic approach to her practice, which requires assessing beyond the physical aspects of a patient's recovery. In terms of modifying her practice of mentorship, P14 emphasized that she would tell others to "allow" patients "to express their fears and give them the appropriate reassurance." P12 remarked that the evidence in the installation emphasized the "intense feelings that people were feeling, on top of the physical insults, . . . all the emotional insults." However, she found that uptake of this research into practice is restricted by the system's focus on efficiency that "dictates your goals ... I can't help the fact that if I don't get this person out in five days ... the higher ups at the hospital or Ministry are going to come down to bear" (P12). Despite P12's reference of working to "take into account" patients' experiences, it appears that the KT process is limited by dominant institutional barriers. The element of institutional context from the PARiHS framework is reflected in P12's narrative as a barrier to research uptake. Embedded in the institutional context is a discourse based on efficiencies: "The measureable is going to be whether or not you walk. The measurable is not necessarily did ... [I] make you feel better, allay your fears" (P4). His comment suggests that emotional recovery may not be a measurable outcome and thus, P4 perceives that his own institutional context acts to inhibit the practice of holistic care approaches. P11 observed that to address patients' needs fully, there must be "more staffing ... [and] recognition that that [emotional care] is an expectation." Her comment suggests that the outlined clinical tasks are an important factor affecting whether emotional care is integrated into practice.

Relational components of care. Practitioners' capacity to relate to patients through communicative and other supportive interventions was a common theme in the interviews. Listening, as a communicative intervention, appeared as a main area of practice modification. P7 indicated that based on the installation, her "most important job is to listen to the patient, hear what they're saying before we ... start telling our message, blah, blah, blah, what we expect from them." Similarly, P12 stated, "Now, I'm much more gentle with people and I let them kind of lead the way in some things and listen to their story." P12 elaborated on the importance of listening as a communication skill in cardiovascular care: 
[We need] more time ... more staffing. And then staffing held to a higher quality ... so that any level of mediocrity in staff would not be acceptable ... we only want to have people here that really want to emulate, even in this restricted system, the ideals of what it is to be a patient and what it is to be cared for and what it is to be listened to.

Her comments indicate not only what is possible with a standard of excellence, but also the institutional changes that are required to implement the evidence garnered from the installation. In terms of the evidence, it was not that a particular part of the installation needed to be translated into practice. Rather, it was the concept of humanistic approaches to care as whole that needed to be implemented through communicative strategies such as active listening.

An element of relational practice was related to how participants communicated with patients. As a result of the installation, P18 noted that he was more "aware ... of what [patients] are feeling." Further comments implied the initiation of "permission statements" in P18's medical practice. For example, he said that practitioners could say to patients, "You are probably a different person and you are feeling different ... what do you feel about this?" These types of statements express to patients that others' often feel this way giving them permission to express their feelings. Additionally, P18 considered asking patients "to write something about what they're feeling" because "expressing this [e.g., insecurities, emotions] will help them." His remarks indicate that offering different ways for patients to communicate may facilitate emotional expression. In referring to the installation, P15 observed how it impacted her communication with patients:

The environment was calm and so I could actually focus on it, but really, like these words when they are spoken to me, they're loud and very impacting ... I went back to tell my co-workers to go see the exhibition because it changed me, my perspective on patients ... I changed my practice in a way that will incorporate this kind of care, and they could just be one or two questions, how are you, how do you feel? ... is there anything I can do to make you feel better?

Her words indicate how the installation's content and design had an aesthetic impact and influenced her to reframe communication patterns by using open-ended questions with patients. The installation's purposefully created environment allowed for the evidence to be focused upon in a reflective manner to the point that this participant felt the words were spoken to her. However, P15 also noted that she felt "bombarded" in her practice and that addressing patients' emotions was often done "on top of their work, their work schedule and their checklist." She specifically referred to her colleagues saying, "You don't have to sweet talk to the patient that long, you have a task to do." This comment highlights how the institutional context of research uptake for this participant was situated in a place where some practitioners devalue patient communication. P13's remarks highlight how the form of evidence contained in the installation was impactful because "it was a very visual experience" and that she had "an emotional reaction." It reminded her that she was one of the few practitioners, who spoke with patients before they entered the operating room, stating: "That's my 
opportunity to ... engage with them, and instill some trust in them. I like to think that would help calm them down." Similar to others, she recognized that efforts at communicating with patients could affect them emotionally and psychologically.

Data indicated that arts-informed dissemination can shift practitioners to be more sensitive to patients' subjective experiences, but also reflected the complicating factors related to practice modification. P8 indicated that the installation was "very real ... very raw" and that its "emotional aspect" prompted her to make practice modifications and work to be "more sensitive." Her linguistic use of the modifier "very" emphasizes how the installation as a form of evidence exposed a vulnerable aspect of the human experience in an unrefined way. She indicated that her practice modification was important because sensitivity or lack of it "could affect whether or not [patients] trust healthcare professionals." Specifically, the installation reminded P8 to "keep the patient comfortable ... Are they needing pain medication? Are we explaining everything enough?" But participants also identified KT factors that restricted practice modifications such as expectations related to efficiency and the significance placed on psychomotor skills. P4's statement highlights how patients' expectations within his medical practice and the institutional context of efficiency were viewed as a barrier. P4 stated that patients want "to be seen in a timely manner ... there's just no time to spend time with the patient and the press and the push for efficiency leaves the patient's subjective experience out." Similarly, in terms of mentoring students or new graduates, P10 referred to "skills" competency as "number one" and then, after that, nurses can learn about "what's going on with the patient and family." These comments highlight an institutional context where interventions that promote patient safety and physical recovery take precedence over interventions that promote psychosocial and emotional wellbeing.

Participants' narratives indicated that the installation prompted them to reflect upon patient interactions. Similar to others, P7 indicated that the installation "validated" her practice in terms of the need "to be with patients and how we interact" with them. She described being "immersed" in the installation to the point that six months later, she found "it's still there in my brain ... I could remember that day." Her comment reflects the enduring capacity associated with arts-informed evidence. P11's comment reflects a simplicity to practice modifications, stating, "You don't do much other than ... just holding their hands ... simple words of reassurance." Her linguistic use of "just" and "simple" emphasizes the ease in making practice modifications. P11 referred to how "build[ing] a better rapport with" patients led to the cultivation of "trust and ... you can work better together." According to P14, she has "always spent time with the patient ... I always reassure them ... I will continue to engage ... to a point where l'll take it more seriously." She elaborated by saying, "We become so task oriented, and efficiency is the big word ... everything is measured by numbers and you cannot measure love or care." Her comment speaks to the institutional context as a complicating KT element specifically related to the discourse within cardiovascular care. P13 indicated that the installation "change[d] something in the way I look at [patients] ... their perspective was the truth. I do see that is how they're being treated [like a number]. ... I'm watching for it now." In addition to patient observation, P13 further detailed practice modifications she made in response to patients' stories in the installation: 
I think the patients really recognize that and that's where the trust and other opportunities to develop trust with the patient, giving them the blanket, getting an armboard, holding their hand just for a moment, just so they know, "Yeah, we know you're a person, you're not just something that we're doing something to." ... I've found my voice, not only am I doing those things where I'm observing where it's lacking, I go take on the responsibility ... I'm also telling people now, which is something I didn't do before.

P13's excerpt indicates not only a change in her interactions with patients, but also how she became a patient advocate. Referring to the installation's impact, P13 stated, "Once you've had a paradigm shift it would take something also as strong to shift it again, and until something like that comes along, I think it will still continue to impact me." The idea of a paradigm shift suggests a dramatic and enduring change.

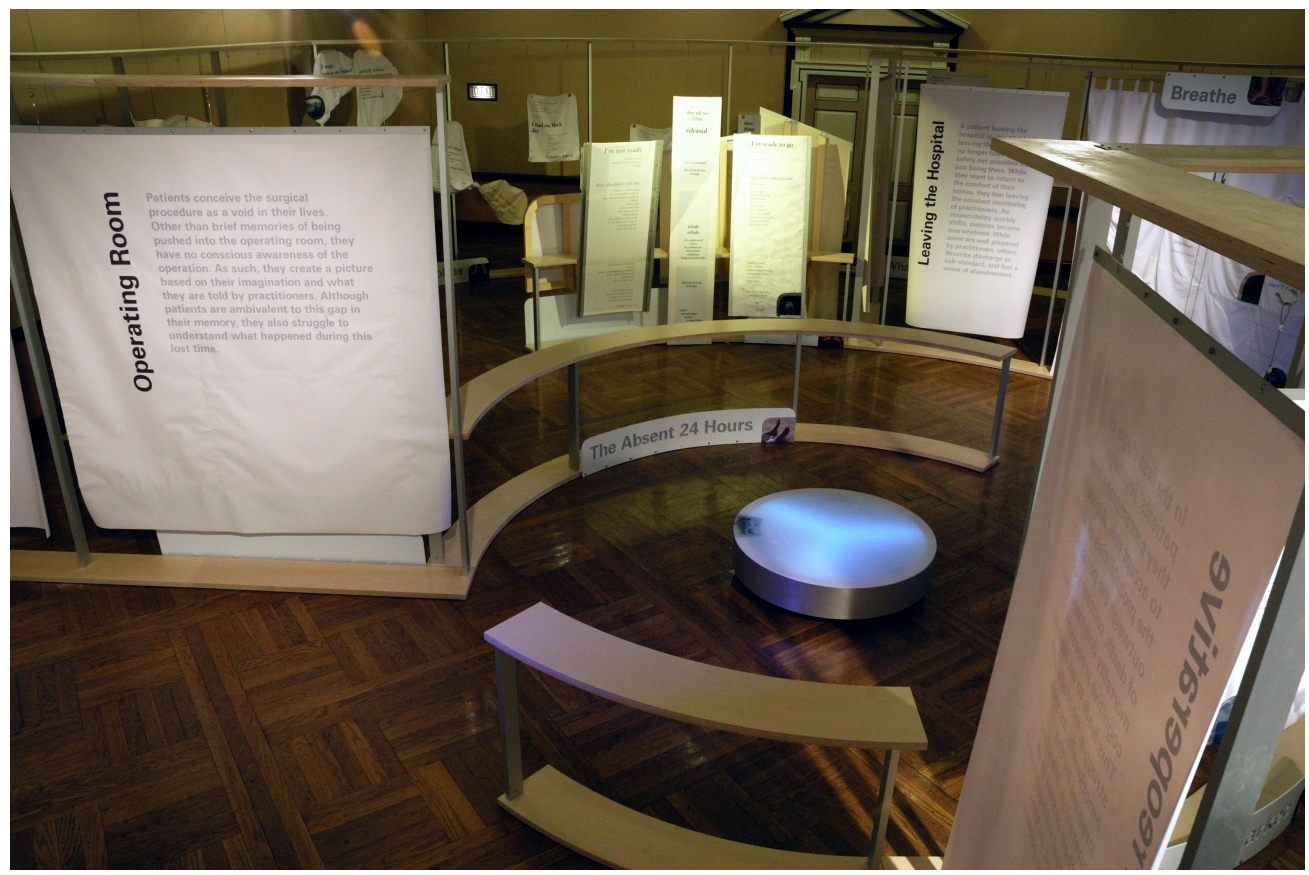

Image 4: Installation Aerial View

\section{Discussion}

"The fact that through a work of art a truth is experienced that we cannot attain in any other way constitutes the philosophical importance of art, which asserts itself against all attempts to rationalize it away" (Gadamer, 1975, pg. xxi)

Gadamer's (1975) assertion concerning art rings true in poignant ways in our study. Practitioners' narratives reflected how they were immersed into patients' journeys so that they could "experience" the art installation as a form of evidence. Although the PARiHS framework speaks to evidence as an influencing element of KT, art as a representational form of evidence has not been considered using this theory. The idea of an experience, via the arts, suggests a sense-based and emotional encounter that can have a personal and enduring impact. Our research corroborates that of others who have explicated an aesthetic quality associated with the arts that stimulates a multitude 
of senses (Bresler, 2006; Greene, 1995; Lapum, et al., 2014). This aesthetic quality can play an instrumental role in KT, considering Dewey's (1934) explanation that the senses are how human beings participate in and make meaning of the world around them. From practitioners' accounts in our study, it appears that art engendered ideas concerning patients' experience that were authentic and indisputable. We further assert that knowledge users would generally not describe traditional dissemination methods, such as journal articles, to be an experience, but rather more comparable to a cognitive and abstract reflection of a topic. Although we do not suggest that art "provide[d] the right answer" (Moon, et al., 2013, pg. 32), it did prompt reflexive thought and, for many, practice modifications aimed at addressing patients' concerns.

Our work supports other health research that has noted the KT capacity of the arts to enhance understanding of the illness experience (Colantonio, et al., 2008; Gray, et al., 2003; Kontos \& Naglie, 2007; Mitchell, et al., 2011). It was common for practitioners in our study to note a shift in their frame of reference that positioned them to understand patients' needs and engage more empathetically. This cognitive change is important, considering that practitioners' capacity for empathy is vital to tailoring decision-making to each patient (Elliot \& Elliot, 1991). Decety and Jackson (2004) observed that empathy is an intentional capacity that can be strengthened through interventions. In the same vein, our research suggests that because of the aesthetic nature of the arts, it may be one type of intervention that can facilitate practitioners' capacity for empathy. What is less clear is how the impact of the arts manifests in behavioral changes, particularly so in a substantive area in which the translation process is dynamic and contingent on the specific patient. For example, the expected practice modifications required to achieve humanistic PCC approaches are neither categorical nor definitive. However, our work has begun to explicate the uptake of research specific to behavioral changes related to holistic and relational patient care approaches, including dynamic communicative and supportive interventions.

The dynamic KT nature of the content of our research (e.g., humanistic PCC approaches) has interesting links with the interpretive form of arts-informed dissemination. Sandelowski and Leeman (2012) have suggested that the dissemination form of qualitative research should be simplified into thematic statements that encapsulate the key ideas. Although our ideas parallel these researchers in terms of how the content of research knowledge is shaped by its presentation form (and, thus, how it is taken up in practice), we diverge from their perspective by proposing that knowledge users be engaged in a co-interpretive process of findings, a suggestion for future KT initiatives. It has been noted that knowledge users are integral to the success of KT and should be actively involved in all research phases (Campbell, 2010; McWilliam, et al., 2009; Reardon, et al., 2006); we suggest that this should include the interpretive process. Specifically, at play with the arts is a broad interpretive quality in which the evidence may be taken up into practice in a myriad of ways. This interpretive quality concerning the translation process can be at odds with traditions engrained in health science research, in which there is ostensibly an objective nature to evidence. However, the assumption of KT as a linear process has been challenged and scholars are beginning to recognize that the process of translating evidence into practice is complex and contingent on the context including the institution, the patient and the 
practitioner (Kitson, et al., 2008). Our team suggests that the complexity of translation lies in its interpretive processes (i.e., making sense of and applying evidence to the particulars of one's context). Although standardization of the strategy would simplify the process, it would also make it less realistic in clinical settings that are often complex, unique, and context-laden (Scott, Rotter, Hartling, Chambers, \& Banner-Martin, 2014). Others have suggested that rather than standardizing interventions, it is better to focus on how and why they work, because often these determinants are unclear (RycroftMalone, et al., 2012). Like Rycroft-Malone et al. (2012), we found that explicating the process-related variables added value to understanding knowledge translation.

Using a theory-informed approach, in our case the PARiHS framework, explicated process-related variables that both facilitated and inhibited research uptake (Rycroft-Malone, 2007). The arts are immersive and sensuous, acting upon participants in powerful ways. In our study, practitioners often noted that the art form made the patients' experiences more real, fortifying the critical importance of humanistic PCC approaches. May (2013) described research implementation "as a complex bundle ... an ensemble of material and cognitive practices" (p. 2). The idea of an ensemble resonated in our work in that KT appeared as a dynamic process with many influencing players in the healthcare environment. We would identify one of these players as the dominant systemic forces that our research highlighted (e.g., biomedical focus on the physical body, psychomotor skills, efficiency, and outcome measures that do not include elements related to PCC). Like others, our study reported that time constraints and limited resources are significant barriers to implementing evidence in the healthcare setting (Ellen, et al., 2014). On the whole, the literature is clear that practitioners' uptake of research is mediated by the context in which they practice (Greenhalgh, Robert, Macfarlane, Bate, \& Kyriakidou, 2004; Montini \& Graham, 2015). Like Montini and Graham, we found that systemic forces restricted practitioners' capacity to make practice modifications. In order to optimize their practice modifications, large systemlevel changes are required (Montini \& Graham, 2015). In accordance with others (Greenhalgh, et al., 2004; Rycroft-Malone, et al., 2004; Rycroft-Malone, et al., 2012), we found that leadership and institutional support were key contextual elements that in our case would support practitioners' capacity to implement research into practice.

Additionally, we surmise that our own lack of focus on the KT element of facilitation may have restricted optimal research uptake. For example, some KT initiatives will involve a knowledge broker to systematically plan and facilitate knowledge translation into practice.

It has been found that education alone may not be optimal at changing practitioners' behaviors and that other KT interventions should be considered (Scott, et al., 2012). Our research extended an understanding of the processes related to how arts-informed dissemination may enhance the KT process, as well as the influencing variables related to context and arts as a form of evidence. The power and innovativeness of the arts may be particularly worthwhile, considering that long-held routines of practice are difficult to change. Methodologically, we found that the uniqueness of arts-informed dissemination may require additional KT strategies. In fact, art often requires dialogue and reflexive thinking (Moon, et al., 2013). Based on study interviews, we suggest that the complexities associated with the interpretive process 
and the influencing KT elements indicate a need to facilitate dialogue and debriefing about the translation process, including deconstructing the evidence within the context of one's own practice. The interpretive and dialogical process may be furthered through the provision of mentors or knowledge brokers in order to facilitate practitioners' knowledge translation capacity (Gagliardi, Webster, \& Straus, 2015; Oliver, Innvar, Lorenc, Woodman, \& Thomas, 2014). Use of knowledge brokers may facilitate the interpersonal processes by being positioned to examine the context where the research is being implemented.

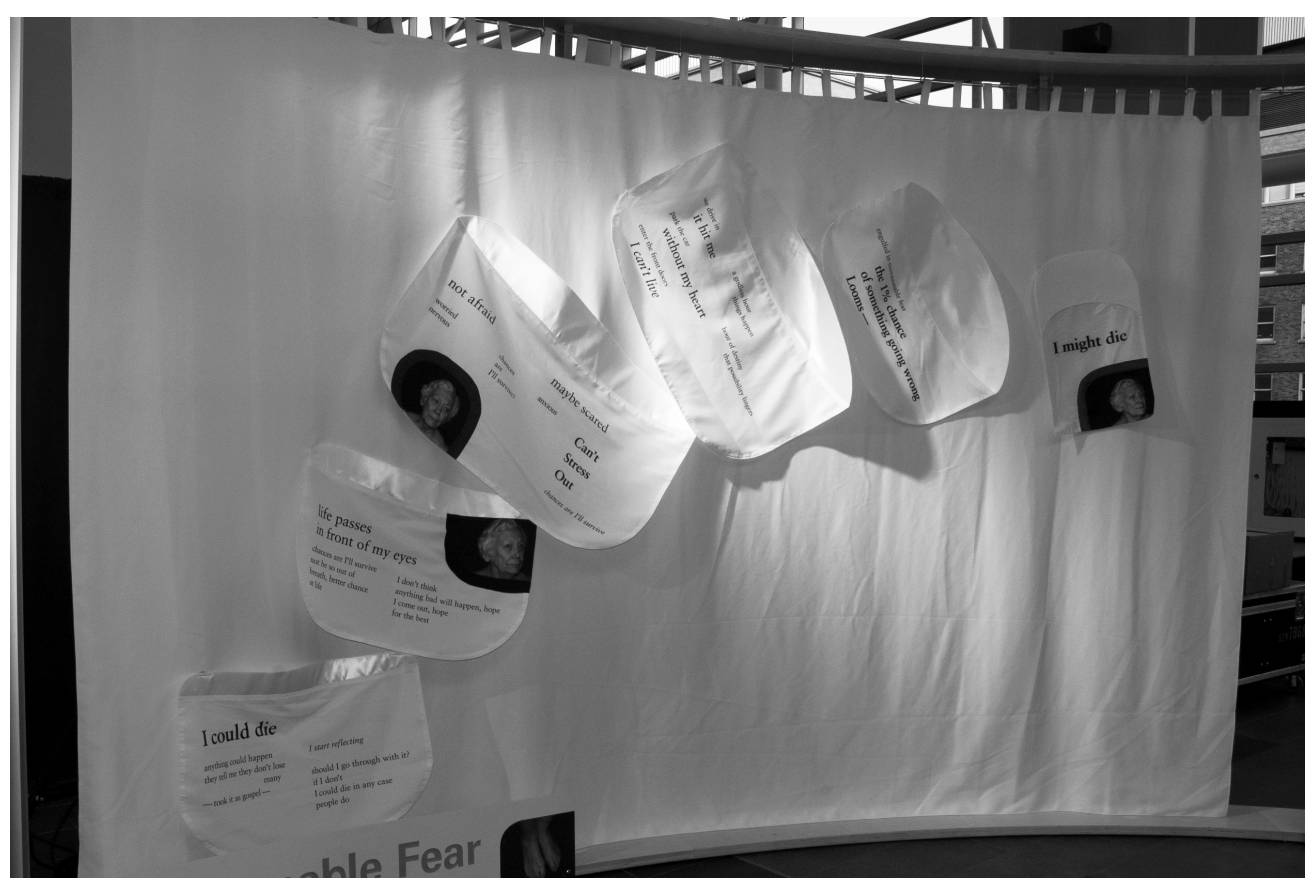

Image 5: Zone 2 - Unreasonable Fear

\section{Conclusions}

In this article, we shared findings from a study that explored how knowledge from a research-derived art installation influenced practice in the cardiovascular field. We found that, as a form of research evidence, the arts have a unique and powerful KT capacity in terms of their aesthetic, experiential, and immersive qualities. There appears to be a restorative power associated with the arts in terms of reminding practitioners about the vital importance of humanistic PCC approaches. However, the interpretive nature of the arts adds a layer of complexity when translating evidence into the practice context. We propose that the dynamic processes associated with research uptake could be optimized through debriefing and other dialogical approaches. Although not exclusive to arts-informed dissemination, it appears that KT elements particularly related to evidence and context require further fleshing out, especially those related to abstract and dynamic practice modifications related to humanistic PCC approaches. Art is not just works of beauty or eccentric paintings or sculptures. Art's imaginative and aesthetic capacities have an undeniable force that can be cultivated with diligence, creativity, and rigour in the world of research and KT. 


\section{Acknowledgments}

We are thankful for the funding provided by the Associated Medical Services as well as the Faculty of Community Services, Ryerson University. We are thankful for the editorial support from Barbara Bauer. We acknowledge the work of the design strategist, Perin Ruttonsha, who worked closely with team members in earlier research phases to design the installation. Last, but not least, we sincerely thank the student volunteers who welcomed visitors to the art installation and provided guidance as necessary. 


\section{References}

Allen, K., \& Wellard, S. (2001). Older women's experiences with sternotomy. International Journal of Nursing Practice, 7(4), 274-279.Canadian Institutes of Health Research (2012). Guide to knowledge translation planning at CIHR: Integrated and end-of-grant approaches. Ottawa, ON: ClHR. Retrieved from: http://www.cihr-irsc.gc.ca/e/29418.html

Carless, D., \& Douglas, K. (2009). Opening doors: Poetic representation of the sport experiences of men with severe mental health difficulties. Qualitative Inquiry, 15(10), 1547-1551.

Charon, R. (2006a). Narrative medicine: Honoring the stories of illness. New York: Oxford University Press.

Charon, R. (2006b). The self-telling body. Narrative Inquiry, 16(1), 191-200.

Colantonio, A., Kontos, P., Gilbert, J., Rossiter, K., Gray, J., \& Keightley, M. (2008). After the crash: research-based theatre for knowledge transfer. Journal of Continuing Education in the Health Professions, 28(3), 180-185.

Cox, S., Brett-MacLean, P., \& Courneya, C. (2016). "My turbinado sugar": Art-making, well-being and professional identity in medical education. Arts \& Health: An International Journal for Research, Policy and Practice, 8(1), 65-81.

Cox, S., Kazubowski-Houston, M., \& Nisker, J. (2009). Genetics on stage: public engagement in health policy development on preimplantation genetic diagnosis. Social Science \& Medicine, 68(8), 1472-1480.

Cummings, G., Estabrooks, C., Midodzi, W., Wallin, L., \& Hayduk, L. (2007). Influence of organizational characteristics and context on research utilization. Nursing Research, 56(Suppl), S24-39.

D'Alessandro, P., \& Frager, G. (2014). Theatre: An innovative teaching tool integrated into core undergraduate medical curriculum. Arts \& Health, 6(3), 191-204.

Decety, J., \& Jackson, P. (2004). The functional architecture of human empathy. Behavioral and Cognitive Neuroscience Reviews, 3(2), 71-100.

Dewey, J. (1934). Art as experience. New York: The Berkley Publishing Group.

Dingley, C., Bush, H., \& Roux, G. (2001). Inner strength in women recovering from coronary artery disease: A grounded theory. The Journal of Theory Construction and Testing, 5(2), 45-52. 
Doucet, A., \& Mauthner, N. (2008). What can be known and how? Narrated subjects and the listening guide. Qualitative Research, 8(3), 399-409.

Eisner, E. (2008). Art and knowledge. In G. Knowles \& A. Cole (Eds.), Handbook of the arts in qualitative research (pp. 3-12). Los Angeles: Sage.

Ellen, M., Leon, G., Bouchard, G., Ouimet, M., Grimshaw, J., \& Lavis, J. (2014). Barriers, facilitators and views about next steps to implementing supports for evidence-informed decision-making in health systems: A qualitative study. Implementation Science, 9(179), 1-12.

Elliot, C., \& Elliot, B. (1991). From the patient's point of view: medical ethics and the moral imagination. Journal of Medical Ethics, 17(4), 173-178.

Fancourt, D., \& Joss, T. (2015). Aesop: A framework for developing and researching arts in health programmes. Arts \& Health, 7(1), 1-13.

Faulkner, S. (2007). Concern with craft: Using ars poetica as criteria for reading research poetry. Qualitative Inquiry, 13(2), 218-234.

Fraser, K., \& al Sayah, F. (2011). Arts-based methods in health research: A systematic review of the literature. Arts \& Health, 3(2), 110-145.

Gadamer, H.-G. (1975). Truth and method. New York, NY: Continuum Press.

Gagliardi, A., Webster, F., \& Straus, S. (2015). Designing a knowledge translation mentorship program to support the implementation of evidence-based innovations. BMC Health Services Research, 15(198), 1-9.

Gray, R., Fitch, M., Labreque, M., \& Greenberg, M. (2003). Reactions of health professionals to a research-based theatre production. Journal of Cancer Education, 18(4), 223-229.

Greene, M. (1995). Releasing the imagination: Essays on education, the arts, and social change. San Francisco: Jossey-Bass.

Greenhalgh, T., Robert, G., Macfarlane, F., Bate, P., \& Kyriakidou, O. (2004). Diffusion of innovations in service organizations: Systematic review and recommendations. The Milbank Quarterly, 82(4), 581-629.

Grimshaw, J., Eccles, M., Lavis, J., Hill, S., \& Squires, J. (2012). Knowledge translation of research findings. Implementation Science, 7(50), 1-17.

Josselson, R., Lieblich, A., \& McAdams, D. (2003). Up close and personal: The teaching and learning of narrative research. Washington, D.C.: American Psychological Association. 
Keller, C. (1991). Seeking normalcy: The experience of coronary artery bypass surgery. Research in Nursing \& Health, 14(3), 173-178.

King, K. (2000). Gender and short-term recovery from cardiac surgery. Nursing Research, 49(1), 29-36.

King, K., \& Jensen, L. (1994). Preserving the self: women having cardiac surgery. Heart \& Lung, 23(2), 99-105.

King, K., Rowe, M., Kimble, L., \& Zerwic, J. (1998). Optimism, coping, and long-term recovery from coronary artery surgery in women. Research in Nursing \& Health, 21(1), 15-26.

Kitson, A., Rycroft-Malone, J., Harvey, G., McCormack, B., Seers, K., \& Titchen, A. (2008). Evaluation the successful implementation of evidence into practice using the PARIHS framework: theoretical and practical challenges. Implementation Science, 3(1) [Online]. Retrieved from: http://www.implementationscience.com/content/3/1/1. doi:10.1186/1748-5908-3-1

Kleinman, A. (1988). The illness narratives: Suffering, healing \& the human condition. New York: Basic Books.

Knowles, J. G., \& Cole, A. (Eds.). (2008). Handbook of the arts in qualitative research. Thousand Oaks, CA: Sage Publications, Inc.

Kontos, P., \& Naglie, G. (2007). Expressions of personhood in Alzheimer's disease: an evaluation of research-based theatre as a pedagogical tool. Qualitative Health Research, 17(6), 799-811.

Lahman, M., Geist, M., Rodriguez, K., Graglia, P., Richard, V., \& Schendel, R. (2010). Poking around poetically: Research, poetry, and trustworthiness. Qualitative Inquiry, 16(1), 39-48.

Lapum, J. (2005). Women's experiences of heart surgery recovery: A poetical dissemination. Canadian Journal of Cardiovascular Nursing, 15(3), 12-20.

Lapum, J. (2009). Patients' narratives of open-heart surgery: Emplotting the technological. Unpublished PhD dissertation, University of Toronto, Toronto, ON. Retrieved from: http://hdl.handle.net/1807/17789.

Lapum, J., Angus, J., Peter, E., \& Watt-Watson, J. (2010). Patients' narrative accounts of open-heart surgery and recovery: Authorial voice of technology. Social Science \& Medicine, 70(5), 754-762.

Lapum, J., Angus, J., Peter, E., \& Watt-Watson, J. (2011). Patients' discharge experiences: Returning home following open-heart surgery. Heart \& Lung: The Journal of Acute and Critical Care, 40(3), 226-235. 
Lapum, J., Church, K., Yau, T., Matthews David, A., \& Ruttonsha, P. (2012). Artsinformed dissemination: Patients' perioperative experiences of open-heart surgery. Heart \& Lung: The Journal of Acute and Critical Care, 41(5), e4-e14.

Lapum, J., Church, K., Yau, T., Ruttonsha, P., \& Matthews David, A. (2013). Narrative accounts of recovering at home following heart surgery. Canadian Medical Association Journal, 185(14), E693-697.

Lapum, J., Hamzavi, N., Veljkovic, K., Mohamed, Z., Pettinato, A., Silver, S., et al. (2012). A performative and poetical narrative of critical social theory in nursing education: An ending and threshold of social justice. Nursing Philosophy, 13(1), 27-45.

Lapum, J., Liu, L., Church, K., Yau, T., Ruttonsha, P., Matthews David, A., et al. (2014). Arts-informed research dissemination in the health sciences: An evaluation of peoples' responses to "The 7,024th Patient" art installation. Sage Open, (Jan.March) 1-14. DOI: 10.1177/2158244014524211

Lapum, J., Liu, L., Hume, S., Wang, S., Nguyen, M., Harding, B., et al. (2015). Pictorial narrative mapping as a qualitative analytic technique. International Journal of Qualitative Methods, 14(5),1-15.

Lapum, J., Ruttonsha, P., Church, K., Yau, T., \& Matthews David, A. (2012). Employing the arts in research as an analytical tool and dissemination method: Interpreting experience through the aesthetic. Qualitative Inquiry, 18(1), 100-115.

Lapum, J., Yau, T., \& Church, K. (2015). Arts-based research: Patient experiences of discharge. British Journal of Cardiac Nursing, 10(2), 80-84.

Lapum, J., Yau, T., Church, K., Ruttonsha, P., \& Matthews David, A. (2015). Unearthing emotions through art: Reflective practice using poetry and photographic imagery. Journal of Medical Humanities, 36(2), 171-176.

Leggo, C. (2004). Living poetry: Five ruminations. Language \& Literacy, 6(2), [Online]. Retrieved from: http://www.langandlit.ualberta.ca

Leichner, P., \& Wieler, C. (2015). maladjusted: Participatory theatre about humancentred care. Arts \& Health, 7(1), 75-85.

Lieblich, A., Tuval-Mashiach, R., \& Zilber, T. (1998). Narrative research: Reading, analysis, and interpretation (vol. 47). Thousand Oaks, CA: Sage.

Lieblich, A., Zilber, T., \& Tuval-Mashiach, R. (2008). Narrating human actions: The subjective experience of agency, structure, communion, and serendipity. Qualitative Inquiry, 14(4), 613-631. 
Macbeth, D. (2001). On "reflexivity" in qualitative research: Two readings, and a third. Qualitative Inquiry, 7(1), 35-68.

May, C. (2013). Towards a general theory of implementation. Implementation Science, $8(18), 1-14$.

McWilliam, C., Kothari, A., Ward-Griffin, C., Forbes, D., Leipert, B., \& Collaboration, S. W. C. C. A. H. C. (2009). Evolving the theory of praxis of knowledge translation through social interaction: A social phenomenological study. Implementation Science, 4(26), 1-14.

Mitchell, G., Dupuis, S., \& Jonas-Simpson, C. (2011). Countering stigma with understanding: The role of theatre in social change and transformation. Canadian Theatre Review, 146(22), 22-27.

Mitchell, G., Jonas-Simpson, C., \& Ivonoffski, V. (2006). Research-based theatre: The making of I'm still here! Nursing Science Quarterly, 19(3), 198-206.

Montini, T., \& Graham, I. (2015). "Entrenched practices and other biases": Unpacking the historical, economic, professional, and social resistance to deimplementation. Implementation Science, 10(24), 1-8.

Moon, S., Rose, S., Black, A., Black, J., Hwang, Y., Lynn, L., et al. (2013). Releasing the social imagination: Art, the aesthetic experience, and citizenship in education. Creative Education, 4(3), 223-233.

Murray, J., O'Farrell, P., \& Huston, P. (2000). The experiences of women with heart disease: What are their needs? Canadian Journal of Public Health, 91(2), 98102.

Oliver, K., Innvar, S., Lorenc, T., Woodman, J., \& Thomas, J. (2014). A systematic review of barriers to and facilitators of the use of evidence by policymakers. BMC Health Services Research, 14(2), 1-12.

Parsons, J., \& Boydell, K. (2012). Arts-based research and knowledge translation: Some key concerns for health-care professionals. Journal of Professional Care, 26(3), 170-172.

Plach, S., \& Heidrich, S. (2001). Women's perceptions of their social roles after heart surgery and coronary angioplasty. Heart \& Lung, 30(2), 117-127.

Plach, S., \& Heidrich, S. (2002). Social role quality, physical health, and psychological well-being in women after heart surgery. Research in Nursing \& Health, 25(3), 189-202.

Radley, A., \& Taylor, D. (2003). Images of recovery: A photo-elicitation study on the hospital ward. Qualitative Health Research, 13(1), 77-99. 
Reardon, R., Lavis, J., \& Gibson, J. (2006). From research to practice: A knowledge transfer planning guide. Toronto, ON: Institute for Work and Health. Retrieved from: http://www.iwh.on.ca/from-research-to-practice.

Rich, M., Polvinen, J., \& Patashnick, J. (2005). Visual narratives of the pediatric illness experience: Children communicating with clinicians through video. Child and Adolescent Psychiatric Clinics of North America, 14(3), 571-587.

Richardson, L. (2002). Poetic representations in interviews. In J. F. Gubrium \& J. A. Holstein (Eds.), Handbook of interview research: Context and method (pp. 877891). Thousand Oaks, CA: Sage.

Rossiter, K., Gray, J., Kontos, P., Keightley, M., Colantonio, A., \& Gilbert, J. (2008). From page to stage: Dramaturgy and the arts of interdisciplinary translation. Journal of Health Psychology, 13(2), 277-286.

Rycroft-Malone, J. (2004). The PARIHS framework - a framework for guiding the implementation of evidence-based practice. Journal of Nursing Care Quality, 19(4), 297-304.

Rycroft-Malone, J. (2007). Theory and knowledge translation: Setting some coordinates. Nursing Research, 56(4S), S78-S85.

Rycroft-Malone, J., Dopson, S., Degner, L., Hutchinson, A., Morgan, D., Stewart, N., \& Estabrooks, C. (2009). Study protocol for the translating research in elder care (TREC): Building context through case studies in long-term care project (project two). Implementation Science, 4(53), 4-53.

Rycroft-Malone, J., Harvey, G., Seers, K., Kitson, A., McCormack, B., \& Titchen, A. (2004). An exploration of the factors that influence the implementation of evidence into practice. Journal of Clinical Nursing, 13(8), 913-924.

Rycroft-Malone, J., Seers, K., Crichton, N., Chandler, J., Hawkes, C., Allen, C., et al. (2012). A pragmatic cluster randomized trial evaluating three implementation interventions. Implementation Science, 7(80), 1-17.

Sandelowski, M., \& Leeman, J. (2012). Writing usable qualitative health research findings. Qualitative Health Research, 22(10), 1404-1413.

Scott, S., Albrecht, L., O'Leary, K., Ball, G., Hartling, L., Hofmeyer, A., et al. (2012). Systematic review of knowledge translation strategies in the allied health professions. Implementation Science, 7(70), 1-17.

Scott, S., Rotter, T., Hartling, L., Chambers, T., \& Banner-Martin, K. (2014). A protocol for a systematic review of the use of process evaluations in knowledge translation research. Systematic Reviews, 3(149), 1-7. 
Shapiro, J., \& Hunt, L. (2003). All the world's a stage: The use of theatrical performance in medical education. Medical Education, 37(10), 922-927.

Sinding, C., Gray, R., Fitch, M., \& Greenberg, M. (2006). Audience responses to a research-based drama about life after breast cancer. Psycho-Oncology, 15(8), 694-700.

Strauss, S., Tetroe, J., \& Graham, I. (2009). Defining knowledge translation. Canadian Medical Association Journal, 181(3-4), 165-168.

Stuckey, H. (2009). Creative expression as a way of knowing in diabetes adult health education: An action research study. Adult Education Quarterly, 60(1), 46-64.

Stuckey, H., \& Tisdell, E. (2010). The role of creative expression in diabetes: an exploration into the meaning-making process. Qualitative Health Research, 20(1), $42-56$.

Ward, V., House, A., \& Hamer, S. (2009). Knowledge brokering: Exploring the process of transferring knowledge into action. BMC Health Services Research, 9(12), 1-6. 